\title{
Clinical experience of the efficacy and safety of low dose tolvaptan therapy in a UK tertiary oncology setting
}

DOI:

10.1210/clinem/dgab131

\section{Document Version}

Accepted author manuscript

Link to publication record in Manchester Research Explorer

\section{Citation for published version (APA):}

Chatzimavridou-grigoriadou, V., Al-othman, S., Brabant, G., Kyriacou, A., King, J., Blackhall, F., Trainer, P. J., \& Higham, C. E. (2021). Clinical experience of the efficacy and safety of low dose tolvaptan therapy in a UK tertiary oncology setting. The Journal of Clinical Endocrinology \& Metabolism. https://doi.org/10.1210/clinem/dgab131

\section{Published in:}

The Journal of Clinical Endocrinology \& Metabolism

\section{Citing this paper}

Please note that where the full-text provided on Manchester Research Explorer is the Author Accepted Manuscript or Proof version this may differ from the final Published version. If citing, it is advised that you check and use the publisher's definitive version.

\section{General rights}

Copyright and moral rights for the publications made accessible in the Research Explorer are retained by the authors and/or other copyright owners and it is a condition of accessing publications that users recognise and abide by the legal requirements associated with these rights.

\section{Takedown policy}

If you believe that this document breaches copyright please refer to the University of Manchester's Takedown Procedures [http://man.ac.uk/04Y6Bo] or contact uml.scholarlycommunications@manchester.ac.uk providing relevant details, so we can investigate your claim.

\section{OPEN ACCESS}


Clinical experience of the efficacy and safety of low dose tolvaptan therapy in a UK tertiary oncology setting.

Victoria Chatzimavridou-Grigoriadou ${ }^{1,2}$, Sami Al-Othman ${ }^{1}$, Georg Brabant ${ }^{1,2}$, Angelos Kyriacou ${ }^{1}$, Jennifer King ${ }^{3}$, Fiona Blackhall ${ }^{2,4}$, Peter J Trainer ${ }^{1,2}$, Claire E Higham ${ }^{1,2}$.

1 Department of Endocrinology, Christie Hospital NHS Foundation Trust, Manchester, UK

2 University of Manchester, Manchester Academic Health Science Centre, Manchester, UK

3 Department of Clinical Oncology, Christie Hospital NHS Foundation Trust, Manchester, UK.

4 Department of Medical Oncology, Christie Hospital NHS Foundation Trust, Manchester, UK.

\section{Corresponding author}

Dr Claire E Higham, DPhil, FRCP.

Consultant Endocrinologist,

Department of Endocrinology, Christie Hospital NHS Foundation Trust, Manchester, UK.

University of Manchester, Manchester Academic Health Science Centre, Manchester, UK

E-mail: Claire.Higham2@nhs.net

\section{Additional information}

Authors' contributions: Study conception: CEH. Study design: VCG, PJT, CEH. Data collection: VCG, SAO, AK, JK. Data analysis: VCG, CEH. Interpretation of the findings: All authors. Manuscript preparation and critical revision: All authors.

Ethics approval and consent to participate: This study was conducted as part of a registered quality improvement project (project ID 976) at the Christie Hospital and data were pseudo-anonymised. For this reason, ethics approval or participants' consent were not required for this study. The study was conducted in accordance with the Declaration of Helsinki.

Consent for publication: All authors have reviewed this version of the manuscript and approved submission and potential publication to the Journal of Clinical Endocrinology and Metabolism. 


\section{Conflict of interest:}

VCG, SAO, GB, JK, FB, PJT, CEH: The authors declare no conflict of interest.

AK: Reimbursement by Otsuka for attending a conference, outside the submitted work.

Funding: No funding was received for the conduct of this retrospective study. VCG was supported by an Academic Clinical Fellowship by the National Institute for Health Research (NIHR). 


\begin{abstract}
Background: In patients with cancer, hyponatraemia is associated with increased morbidity and mortality and can delay systemic therapy.

Methods: The safety and efficacy of low-dose tolvaptan $(7.5 \mathrm{mg})$ for hospitalized, adult patients with hyponatraemia due to Syndrome of Inappropriate Antidiuresis (SIAD), and co-existing malignancy were retrospectively evaluated in a tertiary cancer centre.

Results: Fifty-five patients with mean baseline serum sodium (s $\mathrm{Na}$ ) $117.9 \pm 4.6 \mathrm{mmol} / \mathrm{L}$ were included. $90.9 \%$ had severe hyponatraemia $(\mathrm{sNa}<125 \mathrm{mmol} / \mathrm{L}$ ). Mean age was $65.1 \pm 9.3$ years. Following an initial dose of tolvaptan $7.5 \mathrm{mg}$, median (range) increase in sNa observed at 24 hours was 9(1-19) $\mathrm{mmol} / \mathrm{L}$. Within one week, 39 patients $(70.9 \%)$ reached $\mathrm{sNa} \geq 130 \mathrm{mmol} / \mathrm{L}$ and $48(87.3 \%)$ had $\mathrm{sNa}$ rise of $\geq 5 \mathrm{mmol} / \mathrm{L}$ within 48 hours. No severe adverse events were reported. Thirty-three $(60 \%)$ and seventeen (30.9\%) patients experienced sNa rise of $\geq 8$ and $\geq 12 \mathrm{mmol} / \mathrm{L} / 24 \mathrm{hrs}$, respectively. The rate of $s \mathrm{Na}$ correction in the first 24 hours was significantly higher among participants that continued fluid restriction after tolvaptan administration (median[quantiles]: 14 [9-16] versus 8 [5-11] mmol/L, $\mathrm{p}=0.036$ ). Moreover, in the over-rapid correction cohort ( $\geq 12 \mathrm{mmol} / \mathrm{L} / 24 \mathrm{hrs})$ demeclocycline was appropriately discontinued only in $60 \%$ compared to $91.7 \%$ of the remaining participants ( $P=0.047)$. Lower creatinine was predictive of higher sNa correction rate within 24 hours $(p=0.01)$.

Conclusion: In the largest series to date, although low-dose tolvaptan was demonstrated to be effective in correcting hyponatraemia due to SIAD in cancer patients, a significant proportion experienced over-rapid correction. Concurrent administration of demeclocycline and/or fluid restriction must be avoided due to the increased risk of over-rapid correction.
\end{abstract}

Key words: Hyponatraemia, SIAD, cancer, tolvaptan, safety 


\section{Introduction}

Hyponatraemia secondary to the Syndrome of Inappropriate Antidiuresis (SIAD) is common in patients with cancer, with up to $15 \%$ of patients with Small Cell Lung Cancer (SCLC) being affected (i).

Hyponatraemia in this setting can be well tolerated but a significant number of patients are symptomatic, requiring repeated hospital admissions, long-term medical therapy for hyponatraemia (ii) and may experience delays in systemic anti-cancer therapy. In addition, hyponatraemia appears to be an independent risk factor for mortality (iii), with a previous study suggesting improved survival with resolution of severe hyponatraemia (iv). A multicentre, retrospective, Italian study in cancer patients with SIAD showed that the severity and non-correction of hyponatraemia were significantly correlated with reduced overall survival. It also showed a longer length of hospitalisation in hyponatraemic patients whose serum sodium ( $\mathrm{sNa}$ ) did not normalise (v).

Treatment of hyponatraemia in the oncology setting can be challenging. Firstly, ascertainment of the cause of hyponatraemia is crucial, as treatment differs according to the underlying cause and the extracellular fluid (ECF) volume status of the patient. In addition, hyponatraemia due to SIAD can be persistent as a result of ongoing, tumour-driven inappropriate arginine vasopressin (AVP) secretion. Treatment of the underlying tumour is the only curative intervention, but this is often not possible, for example in the palliative treatment setting or when anticancer therapeutic interventions have been exhausted. Available recommended treatments for SIAD include hypertonic saline infusion, fluid restriction, demeclocycline, urea and vasopressin receptor antagonists (vi,vii,viii). There is no oncology specific guidance relating to hyponatraemia, despite unique features in these patients; for example, long-term fluid restriction is often inappropriate as oncology patients are more likely to have high urinary osmolality (1) and be undergoing interventions such as surgery or chemotherapy (e.g. with regimens including platinum-based compounds) where fluid restriction is not optimal. Hypertonic saline is effective in the short term to correct "dangerously" low sNa levels. However, it is not a long-term solution and ideally requires admission to a highly monitored environment due to risk of over-rapid correction, defined as sNa increase $\geq 8 \mathrm{mmol} / \mathrm{L}$ in 8 hours or $\geq 12 \mathrm{mmol} / \mathrm{L}$ in 24 hours. Demeclocycline induces nephrogenic diabetes insipidus in about $60-70 \%$ of patients, thereby raising sNa levels, but this is not well studied in an oncology population (ix) and takes 2-5 days or longer to take effect, hence it is not appropriate in an urgent care setting $(x)$. A recent study evaluating the administration of urea therapy in patients with cancer demonstrated good efficacy and was well tolerated (viii), but it is not commercially available in many countries.

Tolvaptan is an oral, once daily vasopressin-2 receptor antagonist that is effective at correcting hyponatraemia due to SIAD. The original SALT 1 and 2 studies in patients with hyponatraemia due to heart failure, cirrhosis or SIAD used a daily dose of $15 \mathrm{mg}$ and demonstrated a significant rise in sNa within 24 hours of administration (xi). However, the clinical practice guidelines on hyponatraemia management developed jointly by the European Society for Endocrinology, the European Society of Intensive Care Medicine and the European Renal Association - European Dialysis and Transplant Association recommended against the use of vasopressin receptor antagonists in patients with SIAD and profound hyponatraemia, due to the reported risk of over-rapid increase in s $\mathrm{Na}$ (vii).

The major limitation of tolvaptan is the risk of an over-rapid correction of hyponatraemia and the associated risk of central pontine myelinolysis (CPM). The latter is a rare but devastating complication, leading to potentially life-threatening neurological impairment, including quadriplegia, 
pseudobulbar palsy, seizures and coma (ii,xii). A case of central pontine myelinolysis with concomitant use of tolvaptan and diuretics has been reported in the literature (xiii) and it is included in the manufacturer's summary of adverse reactions (xiv). In initial tolvaptan (SALT 1 and 2) trials, the desirable rates of $s \mathrm{Na}$ correction ( $<0.5 \mathrm{mmol} / \mathrm{L} / \mathrm{hr}$ in the first 24 hours) were exceeded in only 4 of the 223 patients in the tolvaptan group (1.8\%) (xi). In a post-hoc analysis of the SALT trials specifically in patients with cancer, no patient exhibited over-rapid correction (xv). However, this has not been the experience of many clinicians and a Cochrane meta-analysis of 14 trials (2058 patients) that included data on over-rapid correction in s $\mathrm{Na}$ comparing vasopressin receptor antagonists versus control (placebo or no treatment) showed their use to be associated with an increased relative risk of $1.67,95 \% \mathrm{Cl}$ (xvi). Oncology patients may also be more at risk of over-rapid correction given their co-morbidities (xvii).

Our experience of over-rapid sNa correction with $15 \mathrm{mg}$ of tolvaptan led to the use of an initial single $7.5 \mathrm{mg}$ dose in our department (xviii). Subsequent pharmacokinetic studies have demonstrated the validity of this approach (xix), and a $7.5 \mathrm{mg}$ tablet is now available (xx).

We report here a retrospective analysis of the efficacy and safety of tolvaptan $7.5 \mathrm{mg}$ as starting dose for the treatment of hyponatraemia due to SIAD, in a real-life oncology setting, at the Christie Hospital between 2010- 2018.

\section{Methods}

Study design

A retrospective cohort study was conducted including all consecutive hospitalized adult ( $>18$ years) patients with hyponatraemia due to SIAD and co-existing malignancy treated with tolvaptan at an initial dose of $7.5 \mathrm{mg}$ between 2010-2018, in a tertiary cancer centre (Christie NHS Foundation Trust). Patients were identified from the Trust pharmacy database. This study was conducted as part of a registered quality improvement project (project ID 976) at the Christie hospital and data were pseudo-anonymised.

\section{Study population}

Sixty-eight patients in whom tolvaptan treatment was initiated while inpatients at the Christie Hospital were screened. Fifty-five patients were included in the final analysis and received at least one dose of $7.5 \mathrm{mg}$ of tolvaptan. All the included patients had a diagnosis of SIAD based on clinical and biochemical picture in line with our local guidance, which was informed by a national consensus document (xxi), even if some laboratory values were not available.

Five patients were excluded due to non-availability of their clinical records. Six patients that were treated with $15 \mathrm{mg}$ of tolvaptan as a starting dose and two patients documented as hypovolaemic were also excluded. Five of the included patients were originally reported as part of the aforementioned study from our department by Brabant et al (xviii). 


\section{Data collection}

Data were extracted from clinical notes, drug prescription charts, electronic clinic letters and laboratory results. Baseline characteristics included age, sex, body mass index (BMI), underlying malignancy and liver disease or metastases, alcohol consumption, presenting hyponatraemia symptoms, blood electrolyte levels, renal function and therapies given prior to tolvaptan administration. Data on BMI, liver disease or metastases and alcohol consumption were available in 53 patients. The hyponatraemia diagnostic screening was assessed, including the documentation of ECF volume status, baseline serum (sOsm) and urine osmolality (uOsm), urine sodium (uNa), 9 am cortisol in patients who were not receiving any glucocorticoid therapy, thyroid function and plasma glucose, and the provision of specialist endocrine input. Dose of tolvaptan administered and timing of doses were recorded, as well as appropriate discontinuation of other treatments for hyponatraemia (based on our local guidance, both demeclocycline and fluid restriction, when given as first line treatments, should be discontinued prior to the initiation of tolvaptan, and patients should be advised to drink to thirst). Available serum sodium levels were captured up to 28 days following the first dose of tolvaptan, including measurements at 6 hours, 24, 48 and 72 hours, 1, 2 and 4 weeks.

\section{Tolvaptan effectiveness}

Effectiveness of tolvaptan was measured using the following criteria: the average sNa rise at 24,48 and 72 hours, the proportion of patients with $\mathrm{sNa}>130 \mathrm{mmol} / \mathrm{L}$ within a week since the administration of the first dose of tolvaptan and the percentage of patients with a sNa rise of $\geq 5$ $\mathrm{mmol} / \mathrm{L}$ in 48 hours.

\section{Tolvaptan safety}

To assess the safety of tolvaptan, all documented side effects were recorded with emphasis on any cases of central pontine myelinolysis. Specifically, we took particular note of any neurological disturbances reported in patients' clinical notes and reviewed the reports of any magnetic resonance imaging performed within a month from tolvaptan initiation, for any evidence of central pontine myelinolysis. Significant abnormalities in AST and bilirubin were also assessed. In addition, treatments given for over-rapid correction were explored. The rate of sNa rise within 24 and 48 hours from the administration of the first dose of tolvaptan was assessed and the subgroups of patients with a rise of $\geq 8 \mathrm{mmol} / \mathrm{L}$ and $\geq 12 \mathrm{mmol} / \mathrm{L}$ in 24 hours were specifically evaluated (over-rapid correction subgroups). Potential causes for over-rapid correction were explored. Concurrent administration of other hyponatraemia treatments and biochemical parameters such as baseline sNa, urea and creatinine were also evaluated as possible predictive factors. 


\section{Statistical analysis}

Data were summarized using descriptive statistics. Normally distributed continuous variables were presented as mean \pm standard deviation (SD), non-normally distributed continuous variables were presented as median (range) and categorical variables as percentages. Histograms and Shapiro-Wilk test were used to assess normal distribution of continuous variables. Student's T-test was used to compare normally distributed continuous data and Mann-Whitney $U$ test to compare non-normally distributed data. Fisher's exact test was used to compare dichotomous data, due to the limited number of observations. Linear regression analyses were used to assess whether baseline sodium, creatinine, urea, urinary sodium, BMI or the timing of tolvaptan administration were correlated with the serum sodium correction rate. Univariate analyses were followed by multivariate analyses. Selection of variables was based on previous reports of potential correlation. Evaluation of additional variables was not possible, in view of the relatively limited study population for conducting such analyses. A p-value of $<0.05$ was considered as significant. Statistical analyses were performed using R statistical software, version 3.4.3 (R Foundation for Statistical Computing, Vienna, Austria).

\section{Results}

Demographic and baseline characteristics of the participants are summarized in table 1. In brief, 55 patients (26 females) were included, with a mean $( \pm S D)$ age of $65.1( \pm 9.3)$ years; $76.4 \%$ had SCLC.

\section{Baseline biochemical characteristics}

Severe hyponatraemia ( $\mathrm{sNa}<125 \mathrm{mmol} / \mathrm{L}$ ) at baseline was present in $90.9 \%$ of the patients $(\mathrm{n}=50)$ and moderate hyponatraemia ( $\mathrm{sNa} 125-129 \mathrm{mmol} / \mathrm{L}$ ) in $9.1 \%(\mathrm{n}=5)$. Baseline $\mathrm{sNa}$ (mean \pm SD) was $117.9 \pm 4.6 \mathrm{mmol} / \mathrm{L}$, with a lowest value of $108 \mathrm{mmol} / \mathrm{L}$. Median baseline creatinine was 62 (range 34-94) umol/L and median baseline urea was 4.1 (range 2-14.2) $\mathrm{mmol} / \mathrm{L}$.

Fifty-one patients (92.7\%) had a satisfactory morning or random cortisol ( $\geq 450$ or $200 \mathrm{nmol} / \mathrm{L}$ respectively) $(n=26)$ or a normal Short Synacthen Test $(n=2)$ or were on glucocorticoids $(n=23)$ at the time of presentation with hyponatraemia. Cortisol was not assessed in 4 patients $(7.3 \%)$, but clinical suspicion was low and none of these patients were in the over-rapid correction group. Thyroid function tests (TFTs) were available in $48(87.3 \%$ ) patients (in one of these patients, TFTs were performed two days following tolvaptan administration) and none had overt hypothyroidism.

Serum osmolality was measured in $96.4 \%(n=53)$ and was $<275 \mathrm{mOsm} / \mathrm{kg}$ in all (mean ( \pm SD) 246.6 ( \pm 10.2) $\mathrm{mOsm} / \mathrm{kg}$ ). Urine sodium and urine osmolality were available in $87.3 \%(\mathrm{n}=48)$ and $92.7 \%$ $(n=51)$ respectively and all values were appropriate for the diagnosis of SIAD (uOsm >100 mOsm/kg and $\mathrm{uNa}>20 \mathrm{mmol} / \mathrm{L}$ ). Importantly, none of the included patients were on diuretics at the time of treatment with tolvaptan, as per local guidance. Four patients were previously on diuretics, but these were discontinued at least 48 hours prior to tolvaptan. There was no significant difference in the number of patients with complete biochemical assessment (including sOsm, uOsm and uNa) between the over-rapid correction subgroup with rise in sNa of $\geq 12 \mathrm{mmol} / \mathrm{L}$ in 24 hours, and the 
remaining participants $(\mathrm{p}=0.185)$. Disappointingly, ECF volume status prior to initiation of tolvaptan treatment was only documented in $67.3 \%$ of the patients $(n=37)$, with all cases being classified as euvolaemic.

\section{Initial treatments of hyponatraemia}

Initial treatments given to the total population and to the over-rapid correction subgroups (sNa rise $\geq 8$ and $\geq 12 \mathrm{mmol} / \mathrm{L}$ per 24 hours) are described in Table 2 .

Demeclocycline was discontinued prior to commencement of tolvaptan in $82.4 \%$ ( $n=28 / 34$ ). Among the six patients that continued receiving demeclocycline along with tolvaptan, one patient was not reviewed by the endocrine team, two patients continued demeclocycline despite endocrine advice and in three patients, discontinuation of demeclocycline was not explicitly mentioned in the plan from the endocrine team, however this is part of the local guidance. Fluid restriction was appropriately eased in $69.8 \%(n=30 / 43)$. Discontinuation of fluid restriction was not documented in $18.6 \%(n=8)$. The rate of sNa correction in the first 24 hours of treatment was higher among participants that continued receiving demeclocycline after tolvaptan was administered, although the difference did not reach the level of statistical significance (median [quantiles] 14 [9.5-15.5] mmol/L versus 8 [6.8-11] $\mathrm{mmol} / \mathrm{L}, \mathrm{p}=0.08$ ). While in the over-rapid correction cohort demeclocycline was appropriately discontinued only in $60 \%$ of the participants, the respective percentage was $91.7 \%$ in the remaining participants, $p=0.047$ ). The rate of $s \mathrm{Na}$ correction in the first 24 hours of treatment was also significantly higher among 5 participants whose fluid restriction was not eased prior to tolvaptan initiation, compared to 30 participants where fluid restriction was appropriately eased (median [quantiles]: 14 [9-16] mmol/L versus 8 [5-11] mmol/L, $p=0.036$ ). However, data were missing on whether fluid restriction was eased in 8 participants. Based on the available data, fluid restriction was eased in $62.5 \%$ of the participants in the over-rapid correction group and $92.6 \%$ of the remaining patients ( $p=0.06$, NS trend).

\section{Tolvaptan dosing and administration}

All patients received an initial single dose of $7.5 \mathrm{mg}$ tolvaptan. Subsequent doses, when required, remained $7.5 \mathrm{mg}$ per day, except in $4(7.3 \%)$ patients, in whom the dose was escalated (to $15 \mathrm{mg}$ in 3 patients and up to $60 \mathrm{mg}$ in one patient). More specifically, 18 (32.7\%) participants received a second dose the following day. Within a week, participants received a median [quantiles] of 2 [1-3] doses of tolvaptan. The median cumulative dose of tolvaptan was 15 [7.5-22.5] mg during the same period.

The time of dosing was available in a sub-cohort of 47 patients, of whom 9 patients (19.1\%) received tolvaptan prior to midday (12 pm), 16 (34\%) between midday and $5 \mathrm{pm}$, and $22(46.8 \%)$ after $5 \mathrm{pm}$. 


\section{Tolvaptan effectiveness}

Serum sodium increased by a median (range) of 9 (1-19), 11 (1-25) and 10 (0-22) mmol/L at 24, 48 and 72 hours after the initiation of tolvaptan, respectively.

Thirty-nine patients (70.9\%) reached a $\mathrm{sNa} \geq 130 \mathrm{mmol} / \mathrm{L}$ within one week from initiation of treatment. Fourty-eight patients ( $87.3 \%$ ) had a rise in $\mathrm{sNa}$ of $\geq 5 \mathrm{mmol} / \mathrm{L}$ within 48 hours.

\section{Tolvaptan safety}

33 and 17 patients experienced $\mathrm{sNa}$ rise $\geq 8 \mathrm{mmoL} / \mathrm{L}$ and $\geq 12 \mathrm{mmol} / \mathrm{L}$ at 24 hours, respectively (figure 1). No adverse events were documented and, in particular, there were no reported neurological signs or symptoms suggestive of central pontine myelinolysis. Nine patients out of fifty-three with available data regarding imaging, had an MRI head within a month following tolvaptan treatment. Only in one patient the scan was requested due to over-rapid sNa correction, whereas in the remaining eight patients the scans were requested for reasons not related to tolvaptan treatment. Three out of the eight patients did have a rise in $\mathrm{sNa} \geq 12 \mathrm{mmol} / \mathrm{L}$ in 24 hours. None of these nine scans were reported as central pontine myelinolysis.

Previously reported risk factors for central pontine myelinolysis were assessed (vi). Only two of the participants (one in the over-rapid correction cohort) had a current history of alcohol excess. There were no cases of moderate or severe hypokalaemia (potassium $\leq 3.0 \mathrm{mmol} / \mathrm{L}$ ) and no participants with a baseline $\mathrm{sNa} \leq 105 \mathrm{mmol} / \mathrm{L}$. In addition, there was no significant difference in the number of patients with $\mathrm{BMI}<18$ between the two cohorts (over-rapid correction with sNa increase of $\geq 12$ $\mathrm{mmol} / \mathrm{L}$ in 24 hours, $\mathrm{n}=3$, vs overall cohort, $\mathrm{n}=5$ ). There were no cases of advanced liver disease, and the number of patients with liver metastases did not differ between the two groups (overall cohort $n=23 / 53$ vs over-rapid correction $n=9 / 17, p=0.38$ ).

Significant abnormalities in aspartate aminotransferase (AST) (alanine aminotransferase was not routinely checked in our patients) and bilirubin among patients without liver metastases were assessed, given concerns from the Food and Drug Administration (FDA) regarding liver toxicity due to tolvaptan. Out of the 30 patients without liver metastases, 21 patients had no elevations in AST or bilirubin. Only one patient had an AST of $115 \mathrm{IU} / \mathrm{L}$ (range 5-45) with bilirubin of 25 (range 1-20 umol/L) 4 months post tolvaptan, but at the time was also treated for rectal abscess and disease progression. In the remaining eight patients, AST was $<2$ ULN with normal bilirubin and this recovered spontaneously.

Our current protocol advises urgent discussion with the endocrine team if $\geq 6 \mathrm{mmol} / \mathrm{l}$ rise in serum sodium within first 6 hours or $\geq 8 \mathrm{mmol}$ in 12 hours occurs as hypotonic fluids may be required. Among the patients that experienced an over-rapid increase in sNa in 24 hours ( $\geq 12 \mathrm{mmol} / \mathrm{L}$ ), 7 patients received oral or intravenous hypotonic fluids, while 10 patients did not receive any additional treatment and sNa was monitored without further documented complications. 


\section{Over-rapid correction subgroup}

The 17 patients (30.9\%) with an increase in $s \mathrm{Na} \geq 12 \mathrm{mmol} / \mathrm{L}$ in 24 hours were not significantly different to the overall cohort in terms of age (mean $65.7 \pm 8.8$ ), gender ( $52.9 \%$ female), baseline $\mathrm{sNa}$ (mean $117.6 \pm 3.9 \mathrm{mmol} / \mathrm{L}$ ) and BMI (mean $25.1 \pm 6.6$ ). The majority of the patients, as in the main study group, had an underlying diagnosis of SCLC (table 1). Median (range) increase in sNa in 24 hours was 14 (12-19) mmol/L. Pre-treatment endocrine advice was given in 88.2\% ( $n=15)$ and 6hour blood tests were performed in only $41.2 \%(n=7)$. Time of dosing was documented in $94.1 \%$ $(n=16)$, and in $43.8 \%$ of them $(n=7)$ medication was administered after $5 p m$, with only $12.5 \%(n=2)$ treated prior to midday. However, there was no significant difference in the time of tolvaptan administration in the over-rapid correction group, compared to the remaining participants. $64.7 \%$ of patients ( $n=11$ ) had documented ECF volume status, in all cases as euvolaemic.

\section{Biochemical predictors of over-rapid correction}

Univariate regression analyses revealed that lower creatinine was predictive of higher correction rate of $s \mathrm{Na}$ within the first 24 hours $(\mathrm{p}=0.003$ ). Multiple regression analyses including all candidate variables (baseline sNa, uNa, urea, creatinine, BMI and time of dosing) did not yield statistically significant results. However, significant correlation was observed between urea and creatinine in univariate regression analysis. For this reason, multivariate regression analysis was repeated excluding urea, as the strong correlation with creatinine violates the non-multicollinearity assumption of the model. This analysis supported the predictive value of creatinine $(p=0.047$, table 3).

\section{Discussion}

In a cohort of 55 patients studied retrospectively, we explored the clinical effectiveness and safety of low dose tolvaptan for the management of hyponatraemia in oncology patients with SIAD. All patients received an initial single dose of $7.5 \mathrm{mg}$ tolvaptan, the largest published population treated with this dose. In accordance with local guidelines, in the vast majority of the participants, tolvaptan was administered after failure of conventional treatments to correct hyponatraemia.

Tolvaptan therapy (7.5 mg once daily) led to a median (range) rise in $\mathrm{sNa}$ of 9 (1-19) $\mathrm{mmol} / \mathrm{L}$ within 24 hours, while $>80 \%$ of the participants achieved a rise of at least $5 \mathrm{mmol} / \mathrm{L}$ within 48 hours from initiation. Our results demonstrate a comparable rise in $\mathrm{sNa}$ as that reported with $15 \mathrm{mg} /$ day (xvi). In a multicentre retrospective cohort, 28 patients with SIAD and 39 with Congestive Heart Failure (CHF) were treated with $15 \mathrm{mg}$ of tolvaptan, with a mean $( \pm$ SD) sNa rise in 24 hours after tolvaptan initiation of $8.3( \pm 6.3$ ) and $5.0( \pm 3.7) \mathrm{mmol} / \mathrm{L}$ respectively (xxii). In an observational multicentre study of 358 cancer patients with hyponatraemia and a clinical diagnosis of SIAD, tolvaptan was the most effective treatment, as $78.6 \%$ of patients had a sNa rise of $\geq 5 \mathrm{mmol} / \mathrm{L}$ compared to $41.2 \%$ on hypertonic saline, $35 \%$ on fluid restriction and $22.2 \%$ on demeclocycline (xxiii).

There is a lack of evidence from randomised controlled trials to support the effectiveness of other treatments for hyponatraemia in oncology patients. The use of demeclocycline has been based predominantly on anecdotal experience, case reports and observational cohort studies dating back to the 1970s (ix,xvi,xxiv, xxv, xxvi). Despite its effectiveness in the majority of patients (ix), onset of 
action can be up to 8 days and treatment is limited by potential adverse effect on kidney function, although there are no reports on over-rapid correction. The European clinical practice guidelines on hyponatraemia management recommended against the use of demeclocycline, but advocate for urea therapy (vii). This is due to the evidence so far, that urea treatment though effective, particularly after the second day of treatment, is associated with lower risk of over-rapid correction (xxvii,xxviii,xxix), apart from studies where urea was given intravenously or via nasogastric tube in higher doses (xxx, xxxi). No cases of central pontine myelinolysis were reported following urea treatment (28-32). In the oncology setting, a retrospective review of 36 cancer patients with hyponatraemia due to SIAD treated with oral urea monotherapy, showed a mean increase in $\mathrm{SNa}$ of $5 \pm 3 \mathrm{mmol} / \mathrm{L}$ after 24 hours, with no incidents of over-rapid correction (viii). Limitations of its use are the lack of easy availability in some countries, including the UK, and the unpleasant taste $(\mathrm{x})$, though this can be overcome. (vii).

In our study, over-rapid correction (sNa rise $\geq 12 \mathrm{mmol} / \mathrm{L}$ in $24 \mathrm{hrs}$ ) was observed in $30.9 \%$ of the participants, despite the administration of low dose tolvaptan. This did not lead to any documented, clinically evident complications, however full neurological examination and MRI head were not routinely performed for all patients with over-rapid correction, hence central pontine myelinolysis cannot be completely excluded. SALT 1 and 2 trials suggested few patients experienced over-rapid correction (xi). These results were not corroborated in other RCTs (xvi), in line with our findings. This discrepancy could be due to the higher percentage of hypervolaemic patients included in the SALT trials (40\% and $47 \%$ in the tolvaptan treated groups in SALT 1 and 2 respectively). Particular sensitivity of paraneoplastic SIAD to tolvaptan has been suggested previously (xviii). Morris et al found $25 \%$ of patients with SIAD had over-rapid correction of sNa (>12 mmol/L in 24 hours), compared to $3 \%$ of the congestive cardiac failure group (xxii). Another potential factor is the fact that patients included in the SALT trials had significantly higher mean baseline sNa levels compared to our patients, specifically mean ( \pm SD) sNa in tolvaptan treated patients was $128.7( \pm 4.5)$ and 129.5 $( \pm 3.5)$ in SALT 1 and 2 respectively. In the observational study in cancer patients, $14.1 \%$ of patients treated with tolvaptan had over-rapid correction, which is fewer than in our population, however median baseline sNa was higher at $124 \mathrm{mmol} / \mathrm{L}$ (xxiii). No cases of central pontine myelinolysis were reported in any of those studies. In contrast, no cases of over-rapid correction were reported in an Italian retrospective study involving 37 cancer patients with SIAD that received tolvaptan treatment, even though $30 \%$ also received hypertonic saline. However, specific data on the level of sNa increase in 24 hours were not presented (v).

Lower baseline creatinine was associated with increased sNa correction rate in univariate regression analysis. Consistent results were yielded in a multivariate regression analysis, excluding urea due to significant correlation with creatinine (table 3). Morris et al showed that in the SIAD cohort, age, baseline s $\mathrm{Na}$, serum osmolality, urea, serum creatinine and eGFR were significantly correlated with the magnitude of $\mathrm{sNa}$ increase in the first 24 hours. Baseline $\mathrm{sNa}$ and urea were the strongest predictors of the rate of correction of $\mathrm{sNa}$ (xxii). It has been postulated that low urea levels may reflect increased AVP secretion, leading to higher vasopressin receptor blockade impact on tubular water handling (xxii). Other studies have also found statistically significant negative correlation between baseline $\mathrm{sNa}$ and rate of $\mathrm{sNa}$ increase (xxxii). This is possibly due to the larger amount of excess total body water in patients with lower baseline $\mathrm{sNa}$, which generates higher volumes of available free water for renal excretion when the action of AVP is blocked (xxxii). In our study, baseline sNa was not predictive of the correction rate. We explored if the continuation of 
demeclocycline/fluid restriction was contributing to that, but excluding those patients, baseline sNa still did not predict the correction rate. Our population was complex, given the underlying malignancy, and potentially not adequately powered to yield statistically significant correlation for this factor. In another study that looked into the potential risk factors for over-rapid correction of sNa in patients treated with tolvaptan, a significant association was found between lower Body Mass Index (BMI) and degree of correction (xvii); BMI was not significantly correlated with over-rapid correction in our cohort, which is likely due to the smaller number of patients in our study. A correlation between serum creatinine and BMI has been previously reported in general population and in athletes (xxxiii,xxxiv). Patients with lower creatinine levels are likely to have lower lean body mass and hence may be more prone to the effects of the medication. Extensive studies evaluating over-rapid correction of hyponatraemia, due to different causes, also revealed younger age, female sex, schizophrenia, decreased level of consciousness, vomiting and severe hypokalemia as potential risk factors for over-rapid correction (xxxv, xxxvi). In our cohort, age and sex were not associated with over-rapid correction; none of the participants had severe hypokalemia and we did not collect any data on underlying psychiatric diagnoses. Lethargy, nausea and vomiting at baseline were not more frequently reported among patients with over-rapid correction either, although these are prevalent symptoms in patients with underlying malignancy.

Strict adherence to a treatment protocol could enhance the safety of tolvaptan. In our cohort, the percentage of patients with inappropriate continuation of demeclocycline was significantly higher in the over-rapid correction cohort ( $40 \%$ vs $8.3 \%$ ) and the rate of sNa correction in the first 24 hours was significantly higher among the participants that fluid restriction was not eased prior to tolvaptan initiation. Anecdotal evidence also supports the administration of tolvaptan early in the morning when patients are awake to access fluids with repeat sNa assessment during the routine working day. Early biochemical re-evaluation of sNa 6 hours post-dose allows for early intervention against over-rapid correction.

The over-rapid correction observed even using a dose of $7.5 \mathrm{mg}$ raises the question as to whether a lower dose of tolvaptan could be effective and reduce incidence of over-rapid correction. However, a pharmacokinetic study by Shoaf et al (xix) demonstrated that four patients (40\%) treated with 3.75 $\mathrm{mg}$ of tolvaptan experienced clinically significant decrease in their serum sodium ( $\geq 4 \mathrm{mmol} / \mathrm{L}$ in 4 hours).

The cost of tolvaptan is high and incremental to the dose. Specifically, in the UK, the cost of a $15 \mathrm{mg}$ tablet of tolvaptan is $£ 74.68$. However, recent rising costs of demeclocycline ( $£ 43.2$ per $900 \mathrm{mg}$ daily) and availability of $7.5 \mathrm{mg}$ tablets of tolvaptan ( $£ 44.8$ per tablet, approximately half the cost of $15 \mathrm{mg}$ tablet) make the costs almost equitable (xxxvii). In addition, in some countries, for example in the United States, tolvaptan is available as a generic medication and therefore at a lower cost. There are no studies comparing the cost-effectiveness of these two medications.

Our study has a number of limitations. Firstly, this was a retrospective analysis of routinely collected clinical data in a real-life clinical setting. Therefore, although all patients had been given a diagnosis of SIAD, not all data to support this were documented or available, particularly regarding the ECF volume status and urinary sodium. However, in these cases we accepted the previous experts' clinical diagnosis of SIAD, also considering the high pre-test probability in these patients, that all had underlying SCLC. In addition, the effect of tolvaptan on patients' well-being is challenging to capture 
in a retrospective manner, but given the symptomatic burden of severe hyponatraemia (Table 1), correction would be anticipated to improve well-being. Safety data were captured as part of routine care and therefore, some side effects may have not been documented.

\section{Conclusion}

Use of tolvaptan at an initial dose of $7.5 \mathrm{mg}$ is clinically and cost effective (approximately half the price compared to $15 \mathrm{mg}$ dose). However, even this lower dose is associated with a risk of over-rapid correction of hyponatraemia. Our findings also highlight the need to avoid concurrent administration of demeclocycline and/or fluid restriction with tolvaptan, that further increases the risk of over-rapid correction. Considering the significant proportion of patients experiencing over-rapid correction, we suggest tolvaptan should be administered in only selected cases with specialist input (for instance from endocrine or nephrology team) and where other alternatives (e.g. urea) have been considered, as part of a structured clinical pathway. This should require 6-hourly sNa measurements in the first 24 hours, as per manufacturer's guidance (xxxviii), to allow early intervention in the case of overrapid sNa increase. Moreover, it is crucial for clinicians to ensure the cessation of other therapies (e.g. demeclocycline/fluid restriction) prior to tolvaptan initiation, and that patients are allowed to drink to thirst. Overall, in the oncology setting, tolvaptan, at a starting dose of $7.5 \mathrm{mg}$, can be used to effectively manage hyponatraemia due to SIAD and facilitate earlier systemic anti-cancer therapy.

Data availability: Restrictions apply to the availability of some or all data generated or analyzed during this study to preserve patient confidentiality or because they were used under license. The corresponding author will on request detail the restrictions and any conditions under which access to some data may be provided. 


\section{References}

' Castillo JJ, Vincent M, Justice E. Diagnosis and management of hyponatremia in cancer patients. Oncologist 2012;17:756-65.

ii Adrogué HJ, Madias NE. Hyponatremia. N Engl J Med. 2000;342(21):1581-1589.

iii Holland-Bill L, Christiansen CF, Heide-Jørgensen U, et al. Hyponatremia and mortality risk: a Danish cohort study of 279508 acutely hospitalized patients. Eur J Endocrinol. 2015;173(1):71-81.

iv Balachandran K, Okines A, Gunapala R, Morganstein D, Popat S. Resolution of severe hyponatraemia is associated with improved survival in patients with cancer. BMC Cancer. 2015;15:163.

${ }^{v}$ Berardi R, Mastroianni C, Lo Russo G, et al. Syndrome of inappropriate anti-diuretic hormone secretion in cancer patients: results of the first multicenter Italian study. Ther Adv Med Oncol. 2019;11:1758835919877725.

vi Verbalis JG, Goldsmith SR, Greenberg A, et al. Diagnosis, evaluation, and treatment of hyponatremia: expert panel recommendations. Am J Med 2013;126:S1-42.

vii Spasovski G, Vanholder R, Allolio B, et al. Clinical practice guideline on diagnosis and treatment of hyponatraemia. Eur J Endocrinol 2014;170:G1-47.

viii Nervo A, D'Angelo V, Rosso D, et al. Urea in cancer patients with chronic SIAD-induced hyponatremia: Old drug, new evidence. Clin Endocrinol (Oxf) 2019;90:842-8.

${ }^{i x}$ Miell J, Dhanjal P, Jamookeeah C. Evidence for the use of demeclocycline in the treatment of hyponatraemia secondary to SIADH: a systematic review. Int J Clin Pract 2015;69:1396-417.

${ }^{x}$ Sherlock M, Thompson CJ. The syndrome of inappropriate antidiuretic hormone: current and future management options. Eur J Endocrinol 2010;162 Suppl 1:S13-8.

xi Schrier RW, Gross P, Gheorghiade M, et al. Tolvaptan, a selective oral vasopressin V2-receptor antagonist, for hyponatremia. N Engl J Med 2006;355:2099-112.

xii Lampl C, Yazdi K. Central pontine myelinolysis. Eur Neurol. 2002;47(1):3 - 10.

xiii Malhotra I, Gopinath S, Janga KC, Greenberg S, Sharma SK, Tarkovsky R. Unpredictable nature of tolvaptan in treatment of hypervolemic hyponatremia: case review on role of vaptans. Case Rep Endocrinol. 2014;2014:807054.

xiv US Food \& Drug Administration, US Department of Health and Human Services. Samsca (tolvaptan) tablets. April 2018. https://www.accessdata.fda.gov/drugsatfda docs/label/2018/ 022275s016lbledt.pdf. [Accessed in May 2020].

${ }^{x v}$ Gralla RJ, Ahmad F, Blais JD, et al . Tolvaptan use in cancer patients with hyponatraemia due to the syndrome of inappropriate antidiuretic hormone: a post hoc analysisof the SALT-1 and SALT-2 trials. Cancer Medicine 2017, 6(4):723-729.

xvi Nagler EV, Haller MC, Van Biesen W, Vanholder R, Craig JC, Webster AC. Interventions for chronic non-hypovolaemic hypotonic hyponatraemia. Cochrane Database Syst Rev. 2018 Jun 28;6:CD010965.

xvii Kim Y, Lee N, Lee KE, Gwak HS. Risk factors for sodium overcorrection in non-hypovolemic hyponatremia patients treated with tolvaptan. Eur J Clin Pharmacol. 2020 Feb 13.

xviii Kenz S, Haas CS, Werth SC, Bohnet S, Brabant G. High sensitivity to tolvaptan in paraneoplastic syndrome of inappropriate ADH secretion (SIADH). Ann Oncol 2011;22:2696

xix Shoaf SE, Bricmont P, Dandurand A. Low-dose tolvaptan PK/PD: comparison of patients with hyponatremia due to syndrome of inappropriate antidiuretic hormone secretion to healthy adults. Eur J Clin Pharmacol 2017;73:1399-408.

${ }^{x x}$ European Medicines Agency. Samsca: Summary of Product Characteristics. 2009. Available from: https://www.ema.europa.eu/en/documents/product-information/samsca-epar-product-

information en.pdf [Accessed in February 2020].

xxi Grant P, Ayuk J, Bouloux PM, et al. The diagnosis and management of inpatient hyponatraemia and SIADH. Eur J Clin Invest. 2015;45(8):888-894.

xxii Morris JH, Bohm NM, Nemecek BD, et al. Rapidity of Correction of Hyponatremia Due to Syndrome of Inappropriate Secretion of Antidiuretic Hormone Following Tolvaptan. Am J Kidney Dis. 2018 Jun;71(6): $772-782$.

xxiii Burst V, Grundmann F, Kubacki T, et al. Euvolemic hyponatremia in cancer patients. Report of the Hyponatremia Registry: an observational multicenter international study. Support Care Cancer. 2017 Jul;:25(7):2275-2283.

xxiv Perks WH, Mohr P, Liversedge LA. Demeclocycline in inappropriate A.D.H. syndrome. Lancet. $1976 \operatorname{Dec} 25 ; 2(8000): 1414$. 
xxv Forrest JN Jr, Cox M, Hong C, Morrison G, Bia M, Singer I. Superiority of demeclocycline over lithium in the treatment of chronic syndrome of inappropriate secretion of antidiuretic hormone. $\mathrm{N}$ Engl J Med. 1978 Jan 26;298(4):173-7.

xxvi Trump DL. Serious hyponatremia in patients with cancer: management with demeclocycline. Cancer. 1981 Jun 15;47(12):2908-12.

xxvii Lockett J, Berkman KE, Dimeski G, Russell AW, Inder WJ. Urea treatment in fluid restrictionrefractory hyponatraemia. Clin Endocrinol (Oxf). 2019 Apr;90(4):630-636.

xxviii Coussement J, Danguy C, Zouaoui-Boudjeltia K, et al. Treatment of the syndrome of inappropriate secretion of antidiuretic hormone with urea in critically ill patients. Am $\mathrm{J}$ Nephrol. 2012;35(3):265-70.

xxix Rondon-Berrios H, Tandukar S, Mor MK, et al. Urea for the Treatment of Hyponatremia. Clin J Am Soc Nephrol. 2018 Nov 7;13(11):1627-1632.

${ }^{x x x}$ Decaux G, Unger J, Brimioulle S, Mockel J. Hyponatremia in the syndrome of inappropriate secretion of antidiuretic hormone. Rapid correction with urea, sodium chloride, and water restriction therapy. JAMA. 1982;247(4):471-474.

xxxi Decaux G, Andres C, Gankam Kengne F, Soupart A. Treatment of euvolemic hyponatremia in the intensive care unit by urea. Crit Care. 2010;14(5):R184.

xxxii Tzoulis P, Waung JA, Bagkeris E, et al. Real-life experience of tolvaptan use in the treatment of severe hyponatraemia due to syndrome of inappropriate antidiuretic hormone secretion. Clin Endocrinol (Oxf). 2016;84(4):620 - 626.

xxxiii Vikse BE, Vollset SE, Tell GS, Refsum H, Iversen BM. Distribution and determinants of serum creatinine in the general population: the Hordaland Health Study. Scand J Clin Lab Invest. 2004;64(8):709-722.

xxxiv Banfi G, Del Fabbro M, Lippi G. Relation between serum creatinine and body mass index in elite athletes of different sport disciplines. Br J Sports Med. 2006;40(8):675-678.

xxxv George JC, Zafar W, Bucaloiu ID, Chang AR. Risk Factors and Outcomes of Rapid Correction of Severe Hyponatremia. Clin J Am Soc Nephrol. 2018;13(7):984-992.

xxxvi Woodfine JD, Sood MM, MacMillan TE, Cavalcanti RB, van Walraven C. Derivation and Validation of a Novel Risk Score to Predict Overcorrection of Severe Hyponatremia: The Severe Hyponatremia Overcorrection Risk (SHOR) Score. Clin J Am Soc Nephrol. 2019;14(7):975-982.

xxxvii Joint Formulary Committee. British National Formulary (online) London: BMJ Group and Pharmaceutical Press <http://www.medicinescomplete.com > [Accessed in January 2021].

xxxviii Samsca: Summary of product characteristics. 2014. Available from: https://www.ema.europa.eu/en/documents/product-information/samsca-epar-productinformation en.pdf. [Accessed in January 2021]. 


\section{Figures and tables legends}

Table 1: Baseline characteristics of the included patients (overall study population compared to the subgroups of patients with over-rapid serum sodium correction of at least 8 or $12 \mathrm{mmol} / \mathrm{L}$ in 24hrs). *Other malignancies include non-small cell lung cancer, oesophageal cancer, renal cell carcinoma, lymphoma, myeloma, gliomatosis cerebri, testicular teratoma, adrenal liposarcoma and cholangiocarcinoma. SD: Standard Deviation, sNa: serum sodium, BMI: Body Mass Index.

Table 2: Other treatments received prior to the introduction of tolvaptan in the overall study population and the subgroups of people with $\geq 8$ or $\geq 12 \mathrm{mmol} / \mathrm{L}$ rise in sNa in $24 \mathrm{hrs}$. No significant between-group differences were observed. sNa: serum sodium.

Table 3: Results of the univariate and multiple linear regression analyses. sNa: serum sodium, BMI: Body Mass Index.

Figure 1: Serum sodium ( $\mathrm{s} \mathrm{Na}$ ) increase in 24hours in correlation with baseline $\mathrm{s} \mathrm{Na}$, stratified by treatments administered along with tolvaptan. 
Figures and tables

\begin{tabular}{|c|c|c|c|}
\hline & All participants & $\begin{array}{c}\text { Participants with } \geq 8 \\
\mathrm{mmol} / \mathrm{L} \text { rise in } \mathrm{sNa} \text { in } \\
24 \mathrm{hrs}\end{array}$ & $\begin{array}{c}\text { Participants with } \geq 12 \\
\mathrm{mmol} / \mathrm{L} \text { rise in sNa in } 24 \\
\mathrm{hrs}\end{array}$ \\
\hline $\begin{array}{l}\text { Number of patients, } \\
\mathrm{n}(\%)\end{array}$ & 55 & $33(60 \%)$ & $17(30.9 \%)$ \\
\hline \multicolumn{4}{|c|}{ Demographics } \\
\hline $\begin{array}{l}\text { Age (years, mean } \pm \\
\text { SD) }\end{array}$ & $65.1 \pm 9.3$ & $\begin{array}{l}63.5 \pm 9.6 \\
(p=0.1)\end{array}$ & $\begin{array}{l}65.7 \pm 8.8 \\
(p=0.74)\end{array}$ \\
\hline Female sex, n (\%) & $26(47.3 \%)$ & $\begin{array}{l}15(45.5 \%) \\
(p=0.96)\end{array}$ & $\begin{array}{l}9(52.9 \%) \\
(p=0.85)\end{array}$ \\
\hline $\begin{array}{l}\mathrm{BMI}(\text { mean } \pm \mathrm{SD}, \\
\left.\mathrm{kg} / \mathrm{m}^{2}\right)\end{array}$ & $25.3 \pm 5.3$ & $\begin{array}{l}24.7 \pm 5.8 \\
(p=0.36)\end{array}$ & $\begin{array}{l}25.1 \pm 6.6 \\
(p=0.89)\end{array}$ \\
\hline $\begin{array}{l}\text { Baseline } \mathrm{sNa} \text { (mean } \\
\pm \mathrm{SD}, \mathrm{mmol} / \mathrm{L})\end{array}$ & $117.9 \pm 4.6$ & $\begin{array}{c}117.3 \pm 4.3 \\
(p=0.24)\end{array}$ & $\begin{array}{l}117.6 \pm 3.9 \\
(p=0.71)\end{array}$ \\
\hline \multicolumn{4}{|c|}{ Underlying oncological diagnosis n (\%) } \\
\hline $\begin{array}{l}\text { Small Cell Lung } \\
\text { Cancer }\end{array}$ & $42(76.4 \%)$ & $27(81.8 \%)$ & $14(82.4 \%)$ \\
\hline Other* & $13(23.6 \%)$ & $8(18.2 \%)$ & $3(17.6 \%)$ \\
\hline \multicolumn{4}{|c|}{$\begin{array}{l}\text { Presenting symptoms } \mathbf{n}(\%) \\
\text { nificant between-group differences w }\end{array}$} \\
\hline $\begin{array}{l}\text { Asymptomatic } \\
\text { patients }\end{array}$ & $15(27.3 \%)$ & $9(27.3 \%)$ & $5(29.4 \%)$ \\
\hline Confusion & $11(20 \%)$ & 7 (21.2\%) & $2(11.8 \%)$ \\
\hline Nausea / Vomiting & $11(20 \%)$ & $7(21.2 \%)$ & $4(23.5 \%)$ \\
\hline Fatigue & $7(12.7 \%)$ & $6(18.2 \%)$ & $2(11.8 \%)$ \\
\hline Dizziness & $3(5.5 \%)$ & $2(6.1 \%)$ & $1(5.9 \%)$ \\
\hline Anorexia & $3(5.5 \%)$ & $2(6.1 \%)$ & $0(\%)$ \\
\hline Lethargy & $4(7.3 \%)$ & $3(9.1 \%)$ & $2(11.8 \%)$ \\
\hline
\end{tabular}

Table 1: Baseline characteristics of the included patients (overall study population compared to the subgroups of patients with over-rapid serum sodium correction of at least 8 or $12 \mathrm{mmol} / \mathrm{L}$ in $24 \mathrm{hrs}$ ). *Other malignancies include non-small cell lung cancer, oesophageal cancer, renal cell carcinoma, lymphoma, myeloma, gliomatosis cerebri, testicular teratoma, adrenal liposarcoma and cholangiocarcinoma. SD: Standard Deviation, sNa: serum sodium, BMI: Body Mass Index. 


\begin{tabular}{|c|c|c|c|}
\hline & $\begin{array}{l}\text { All participants } \\
(\mathrm{N}=55) \mathrm{n}(\%)\end{array}$ & $\begin{array}{l}\text { Participants with } \geq 8 \\
\mathrm{mmol} / \mathrm{L} \text { rise in sNa in } \\
24 \mathrm{hrs}(\mathrm{N}=33), \mathrm{n}(\%)\end{array}$ & $\begin{array}{c}\text { Participants with } \geq 12 \\
\mathrm{mmol} / \mathrm{L} \text { rise in sNa in } 24 \mathrm{hrs} \\
(\mathrm{N}=17), \mathrm{n}(\%)\end{array}$ \\
\hline Demeclocycline & 34 (61.8\%) & 23 (69.7\%) & $10(58.8 \%)$ \\
\hline Fluid restriction & 43 (78.2\%) & 25 (75.8\%) & 11 (64.7\%) \\
\hline Hypertonic saline & $1(1.8 \%)$ & $1(3 \%)$ & 0 \\
\hline Salt tablets & $2(3.6 \%)$ & $1(3 \%)$ & 1 (5.9\%) \\
\hline No treatment & 7 (12.7\%) & $5(15.2 \%)$ & $4(23.5 \%)$ \\
\hline
\end{tabular}

Table 2: Other treatments received prior to the introduction of tolvaptan in the overall study population and the subgroups of people with $\geq 8$ or $\geq 12 \mathrm{mmol} / \mathrm{L}$ rise in sNa in $24 \mathrm{hrs}$. No significant between-group differences were observed. sNa: serum sodium. 


\begin{tabular}{|l|l|l|}
\hline Variable & Coefficient & P-value \\
\hline Baseline sNa & -0.199 & 0.155 \\
\hline Urea & -0.445 & 0.117 \\
\hline Creatinine & -0.132 & 0.003 \\
\hline Urine $\mathrm{Na}$ & 0.006 & 0.691 \\
\hline $\mathrm{BMI}$ & -0.067 & 0.595 \\
\hline Timing of first dose & -0.061 & 0.73 \\
\hline Multiple regression analysis (all variables) & NS \\
\hline Multiple regression analysis (excluding urea) & Creatinine, $\mathrm{p}=0.047$ \\
\hline
\end{tabular}

Table 3: Results of the univariate and multiple linear regression analyses. sNa: serum sodium, BMI: Body Mass Index. 


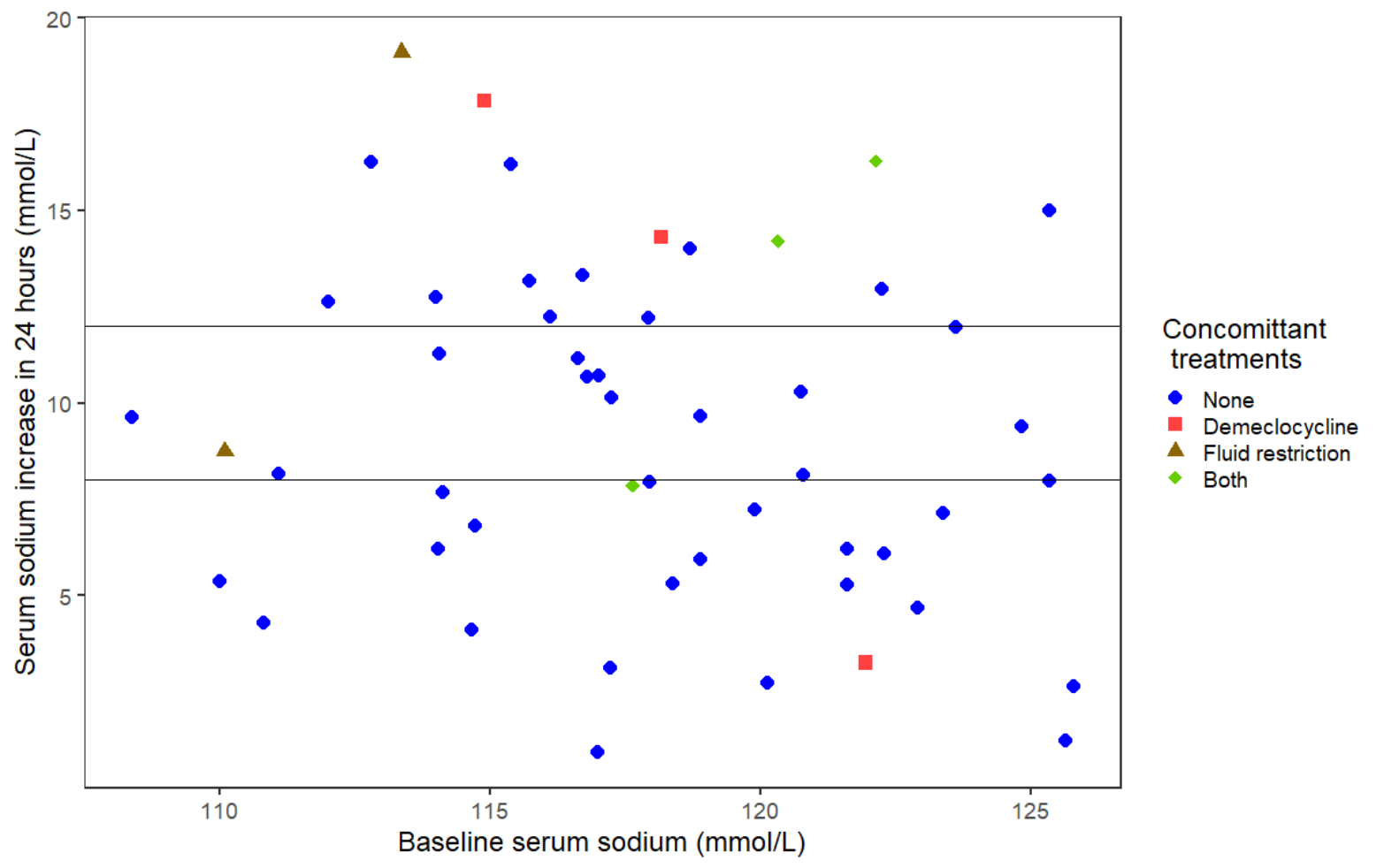

Figure 1: Serum sodium ( $\mathrm{sNa}$ ) increase in 24hours in correlation with baseline sNa, stratified by treatments administered along with tolvaptan. 